\title{
Efeito Alelopático do Fruto de Sapindus saponaria NA Germinação e na Morfologia de Plântulas Daninhas e de HORTALIÇAS ${ }^{1}$
}

\author{
Allelopathic Effect of Sapindus saponaria Fruit on Germination and Seedlings Morphology of \\ Weed and Vegetables
}

GRISI, P.U. ${ }^{2}$, GUALTIERI, S.C.J. ${ }^{3}$, RANAL, M.A. ${ }^{4}$ e SANTANA, D.G. ${ }^{5}$

\begin{abstract}
RESUMO - O objetivo deste estudo foi avaliar o potencial alelopático do extrato aquoso de frutos de Sapindus saponaria (sabão-de-soldado) na germinação de diásporos e na morfologia de plântulas de Lactuca sativa (alface), Allium cepa (cebola), Echinochloa crus-galli (capim-arroz) e Ipomoea grandifolia (corda-de-viola). O extrato aquoso dos frutos foi preparado na proporção de $100 \mathrm{~g}$ de material vegetal fresco para $1.000 \mathrm{~mL}$ de água destilada, produzindo-se a concentração de $10 \%$. A partir dele, foram feitas diluições em água destilada para 7,5, 5,0 e 2,5\%. O extrato do fruto Sapindus saponaria evidenciou potencialidades alelopáticas tanto sobre as espécies de hortaliças quanto sobre as de plantas daninhas. O efeito inibitório sobre o processo de germinação dos diásporos e morfologia das plântulas de alface, cebola, capim-arroz e corda-de-viola foi dependente da concentração. Os resultados mostram o potencial do extrato proveniente dos frutos de Sapindus saponaria como um herbicida a ser utilizado em práticas de agricultura sustentável.
\end{abstract}

Palavras-chave: alelopatia, Allium cepa, Echinochloa crus-galli, Ipomoea grandifolia, Lactuca sativa, sabão-desoldado

\begin{abstract}
The aim of this study was to evaluate the allelopathic potential of the aqueous extract of Sapindus saponaria (soapberry) fruit on seed germination and seedling morphology of Lactuca sativa (lettuce), Allium cepa (onion), Echinochloa crus-galli (barnyard grass), and Ipomoea grandifolia (morningglory). The aqueous extract of the fruit was prepared using $100 \mathrm{~g}$ of fresh plant material dissolved in 1,000 $\mathrm{mL}$ of distilled water, resulting in 10\% concentration. The dilutions were made with distilled water to 7.5, 5.0, and 2.5\%. The Sapindus saponaria fruit extract showed allelopathic potential on the vegetable and weed species. The inhibitory effect on the seed germination process and seedling morphology oflettuce, onion, barnyard grass, and morningglory was concentration dependent. The results showed the potential use of the Sapindus saponaria fruit extract as herbicide in sustainable agricultural practices.
\end{abstract}

Keywords: allelopathy, Allium cepa, Echinochloa crus-galli, Ipomoea grandifolia, Lactuca sativa, soapberry.

\section{INTRODUÇÃO}

As potencialidades alelopáticas das espécies que compõem o agroecossistema proporcionam vasta gama de interações entre as espécies agrícolas, florestais e plantas daninhas, algumas deletérias para a planta receptora, podendo proporcionar vantagem seletiva para o doador (Kohli et al., 2006).

Recebido para publicação em 2.7.2010 e na forma revisada em 6.5.2011.

2 Mestre em Ecologia e Recursos Naturais, Dep. de Botânica, Universidade Federal de São Carlos - UFSCar, Rodovia Washington Luiz, Km 235, Caixa Postal 676, 13565-905 São Carlos-SP, Brasil, <patriciaumeda@hotmail.com>; ${ }^{3}$ Professor titular, Dep. de Botânica, UFSCar, São Carlos-SP, Brasil; ${ }^{4}$ Professor titular, Instituto de Biologia, Universidade Federal de Uberlândia - INBIO/ UFU, Caixa Postal 593, 38400-902 Uberlândia-MG, Brasil; ${ }^{5}$ Professor Adjunto II, Instituto de Ciências Agrárias - ICIAG/UFU. 
Vários estudos mostram que o agroecossistema aumenta a produtividade, melhora a qualidade do solo, o microclima, a ciclagem de nutrientes, conserva o solo, controla as plantas daninhas e gera maior sustentabilidade (Mauli et al., 2009; Young \& Bush, 2009), embora interações negativas, incluindo as alelopáticas, também tenham sido reconhecidas (Kohli et al., 2006). Nesse sentido, práticas culturais, como a adubação verde, associadas ao conhecimento da influência dos aleloquímicos como herbicidas naturais têm visado o manejo sustentável de plantas daninhas (Kohli et al., 2006).

Os princípios ativos para a formulação de herbicidas baseados em produtos naturais têm aumentado, com a vantagem de esses produtos serem parcialmente solúveis em água, exibindo bioatividade em baixas concentrações (Vyvyan, 2002; Maraschin-Silva \& Aqüila, 2006). Dos inúmeros aleloquímicos identificados, o modo de ação deles é pouco conhecido e diversificado, agindo de forma diferente em relação aos herbicidas sintéticos e abrindo novas possibilidades, sobretudo no controle biológico de plantas daninhas resistentes a esses produtos (Vyvyan, 2002).

A resistência ou tolerância aos metabólitos secundários é uma característica inerente à espécie, existindo aquelas mais sensiveis, como Lactuca sativa (alface) e Lycopersicon esculentum (tomate), consideradas plantas indicadoras de atividade alelopática. Para que seja indicada como planta-teste, a espécie deve apresentar germinação rápida e uniforme, tendo sensibilidade suficiente que permita expressar os resultados sob efeito de baixas concentrações de substâncias alelopáticas (Ferreira \& Áquila, 2000). A utilização de espécies de plantas daninhas como indicadoras pode gerar limitações, como a desuniformidade de germinação devido à baixa homogeneidade dos diásporos, diferentemente do que ocorre quando são utilizadas espécies cultivadas em escala comercial (Silva et al., 2009).

Sapindus saponaria pertence à família Sapindaceae e é conhecida vulgarmente por sabão-de-soldado. É uma espécie arbórea nativa, utilizada em paisagismo e na recuperação de áreas degradadas. No Brasil, ocorre desde o Pará até o Rio Grande do Sul, nas florestas pluviais e semideciduais (Albiero et al., 2001). A espécie é conhecida não apenas pela utilização da madeira, mas também pela presença de saponinas, um surfatante natural encontrado nos frutos, que são utilizados como sabão no banho e no combate a úlceras, feridas na pele e inflamações (Albiero et al., 2001; Pelegrini et al., 2008).

As saponinas presentes nos frutos de Sapindus saponaria possuem propriedades tensoativas e farmacológicas. Esses compostos são classificados como triterpenoides e apresentam atividade antiulcerativa e antineoplásica (Albiero et al., 2001). Embora se conheça a composição fitoquímica do fruto dessa espécie e seus efeitos como propriedades farmacêuticas, poucos trabalhos referem-se ao seu potencial alelopático sobre outras espécies de plantas.

Em razão disso, levantou-se a hipótese de que extratos aquosos de frutos de Sapindus saponaria poderiam interferir no estabelecimento das espécies de hortaliças bioindicadoras de alelopatia e das espécies de plantas daninhas. Nesse contexto, o presente estudo teve como objetivo avaliar o potencial alelopático do extrato aquoso de frutos de Sapindus saponaria na germinação de diásporos e na morfologia de plântulas de Lactuca sativa (alface), Allium cepa (cebola), Echinochloa crusgalli (capim-arroz) e Ipomoea grandifolia (cordade-viola).

\section{MATERIAL E MÉTODOS}

\section{Preparação dos extratos}

Os frutos de Sapindus saponaria, de coloração amarelo-translúcida, foram coletados de 10 árvores no município de São Carlos, SP $\left(22^{\circ}\right.$ 02' S e $47^{\circ} 52^{\prime} \mathrm{W}$ ), em julho de 2008. A região é caracterizada pelo tipo climático Aw, segundo o sistema de classificação de Köppen (1948), considerado tropical de altitude com inverno seco (abril a setembro) e verão chuvoso (outubro a março).

A massa dos frutos foi avaliada antes de serem triturados em um liquidificador industrial durante cinco minutos, resultando no material vegetal fresco. O extrato aquoso foi 
preparado na proporção de $100 \mathrm{~g}$ de material vegetal fresco para $1.000 \mathrm{~mL}$ de água destilada, produzindo-se a concentração de $10 \%$. O extrato permaneceu em repouso durante $30 \mathrm{~min}$ a $4{ }^{\circ} \mathrm{C}$ e, em seguida, foi filtrado a vácuo, utilizando-se uma bomba elétrica acoplada a um funil de Buchner forrado internamente com papel-filtro (Gatti et al., 2004). O extrato resultante foi recolhido em um béquer e, a partir dele, foram feitas diluições em água destilada para $7,5,5,0$ e $2,5 \%$.

\section{Caracteristicas físico-quimicas dos extratos}

$\mathrm{O} \mathrm{pH}$ do extrato foi medido com o peagâmetro Analion, modelo PM608, e a concentração molar, com o osmômetro automático ( $\mu$ Osmotte, modelo 5004), calculando-se posteriormente o potencial osmótico do extrato de frutos na maior concentração.

\section{Teste de germinação}

As quatro concentrações obtidas a partir do extrato de frutos foram aplicadas nos diásporos de Lactuca sativa, Allium cepa, Echinochloa crus-galli e Ipomoea grandifolia para avaliação do processo de germinação, em comparação com a aplicação de água destilada (tratamento controle). As sementes de Ipomoea grandifolia foram escarificadas em ácido sulfúrico concentrado durante $5 \mathrm{~min}$ e, em seguida, lavadas em água corrente (Azania et al., 2003).

Foram utilizadas quatro repetições de 30 diásporos, semeados em placas de Petri sobre duas folhas de papel-filtro umedecidas com $5 \mathrm{~mL}$ do extrato ou água. Cada placa foi coberta por uma película de plástico transparente e tampada em seguida para evitar evaporação. $\mathrm{O}$ experimento foi instalado em câmara de germinação a $25^{\circ} \mathrm{C}$, sob fotoperíodo de 12 horas luz/ 12 horas escuro e irradiância média de $12,26 \pm 6,49 \mu \mathrm{mol} \mathrm{m}^{-2} \mathrm{~s}^{-1}$, segundo recomendações de Concenço et al. (2008) e Mauli et al. (2009). O delineamento experimental foi inteiramente casualizado. As leituras foram realizadas a cada 12 horas, durante os sete primeiros dias, e em intervalos de 24 horas, até a estabilização da germinação, adotando-se a protrusão de qualquer parte do embrião como critério de germinação.

Foram avaliados o tempo inicial, final e médio de germinação, a germinabilidade, a velocidade média de germinação $(\bar{v})$, a velocidade de germinação $(V G)$, o coeficiente de variação do tempo, a incerteza e a sincronia (Ranal \& Santana, 2006). Calculou-se também o índice de resposta ao efeito alelopático $(R I)$, expresso matematicamente por $R I=1-(C / T)$, se $T \geq C$, ou $R I=(T / C)-1$, se $T \leq C$, em que $C$ é a velocidade de germinação do controle e $T$ a velocidade de germinação do tratamento (Gao et al., 2009).

Para avaliar o efeito osmótico dos extratos obtidos, foi realizado um bioensaio de germinação com diásporos de Lactuca sativa, Allium cepa, Echinochloa crus-galli e Ipomoea grandifolia em soluções de polietilenoglicol 6000 (PEG 6000) a -0,2 MPa, além do controle (0 MPa), segundo recomendações de Villela et al. (1991). O experimento foi feito utilizandose a mesma metodologia descrita para o bioensaio de germinação.

O termo diásporo foi usado ao longo do texto para designar ambos os tipos de unidades de dispersão estudadas. Para alface e capim-arroz utilizou-se o nome específico de seus diásporos: cipsela e cariopse, respectivamente. $\mathrm{O}$ termo semente foi utilizado para as unidades de dispersão da cebola e corda-de-viola, que não contêm partes do fruto.

\section{Morfologia de plântulas}

Para análise da morfologia de plântulas de alface, cebola, capim-arroz e corda-de-viola, foram transferidas plântulas com $3 \mathrm{~mm}$ de raiz para caixas de plástico transparente $(21,0 \times 14,3 \times 6,0 \mathrm{~cm})$ contendo como substrato papel-filtro umedecido com $15 \mathrm{~mL}$ de água ou extrato de frutos nas mesmas concentrações adotadas no teste de germinação. As caixas foram mantidas em câmara de germinação a $25^{\circ} \mathrm{C}$, com fotoperíodo de 12 horas e irradiância média de 13,38 $\pm 7,96 \mu \mathrm{mol} \mathrm{m}^{-2} \mathbf{s}^{-1}$. Utilizaramse quatro repetições de 20 plântulas, em delineamento experimental inteiramente casualizado. Após sete dias do transplantio, foram avaliados o comprimento da parte aérea, o comprimento da raiz primária e a presença de anomalias. O comprimento da parte aérea, do 
colo até o meristema caulinar, e da raiz primária, do colo até o meristema radicular, foi medido a partir de uma amostra aleatória de 10 plântulas por repetição, utilizando-se paquímetro.

As plântulas foram classificadas em normais e anormais, sendo consideradas anormais aquelas que não mostraram potencial para continuar o seu desenvolvimento, tendo o sistema radicular ou a parte aérea apodrecidos, necrosados, ausentes ou totalmente atrofiados (Brasil, 2009). Também foram quantificadas as plântulas mortas.

\section{Análise estatistica}

Os dados obtidos para cada uma das características avaliadas foram submetidos aos testes de normalidade (Shapiro-Wilk) e homogeneidade (Levene). Quando essas duas pressuposições foram atendidas, foi aplicada a análise de variância (ANOVA), seguida pelo teste de Tukey a 0,05 de significância. A falta de normalidade ou homogeneidade (ou ambas) levou à realização de testes não paramétricos, Kruskal-Wallis, seguido de Dunn para comparações binárias, a 0,01 de significância.

Procedeu-se à regressão linear ou quadrática quando o resultado da ANOVA foi significativo. O ajuste do modelo foi testado a 0,05 de significância e avaliado pelo seu coeficiente de determinação $\left(R^{2}\right)$. As variáveis que não apresentaram diferenças significativas entre os tratamentos foram representadas nas figuras com os valores médios e seus respectivos desvios-padrão.

As equações das regressões lineares foram submetidas ao teste do paralelismo (teste F) para testar a hipótese de nulidade de que as inclinações das equações são estatisticamente iguais, conforme descrito por Sokal \& Rohlf (1997).

\section{RESULTADOS E DISCUSSÃO}

O extrato obtido de frutos frescos de Sapindus saponaria exerceu efeito significativo sobre o processo de germinação dos diásporos das hortaliças estudadas. O início da germinação das cipselas de alface variou entre 24 e 33 horas (Figura 1), e o tempo final de germinação das sementes de cebola foi menor no tratamento controle e nas concentrações de 7,5 e $10 \%$ (Tabela 1). Para as cipselas de alface, houve decréscimo linear na germinabilidade $\left(1,77 \%\right.$ para cada $0,01 \mathrm{mg} \mathrm{mL}^{-1}$ de extrato), na velocidade média de germinação $\left(0,00076\right.$ hora $^{-1}$ para cada $0,01 \mathrm{mg} \mathrm{mL}^{-1}$ de extrato) e na velocidade de germinação $\left(0,0364\right.$ semente hora $^{-1}$ para cada $0,01 \mathrm{mg} \mathrm{mL}^{-1}$ de extrato). Por outro lado, houve aumento linear no tempo médio de germinação, de 2,33 horas para cada $0,01 \mathrm{mg} \mathrm{mL}^{-1}$ de extrato adicionado (Figura 1).

As sementes de cebola apresentaram valores mínimos de germinabilidade na concentração de $7,44 \%$ (53,75\%) e acréscimo linear de 1,69 hora no tempo médio de germinação para cada $0,01 \mathrm{mg} \mathrm{mL}^{-1}$ de extrato adicionado. Em decorrência disso, os menores valores para a velocidade média $\left(0,0124\right.$ hora $\left.^{-1}\right)$ e velocidade de germinação $\left(0,2195\right.$ semente hora $\left.{ }^{-1}\right)$ das sementes de cebola ocorreram nas concentrações de 7,14 e $7,60 \%$, respectivamente (Figura 1).

Verificou-se que as cipselas de alface apresentaram maior velocidade média de germinação do que as sementes de cebola. No entanto, esta última espécie foi a que sofreu maior inibição na porcentagem de germinação, apresentando maior sensibilidade ao efeito do extrato (Figura 1).

De acordo com o teste F, as linhas de tendência das regressões lineares do tempo médio de germinação tiveram as mesmas taxas de incrementos para as duas espécies de hortaliças (Tabela 2). Os valores referentes ao coeficiente de variação do tempo de germinação das sementes de cebola não apresentaram ajuste linear ou quadrático, indicando aumentos e declínios variados, dependendo da concentração; os menores valores médios foram registrados para o tratamento controle e nas concentrações de 7,5 e 10\% (Tabela 1).

A incerteza do processo de germinação das cipselas de alface foi maior na concentração de $7,25 \%(2,81 \mathrm{bits})$, com sincronia minima $(0,13)$ na concentração de $9 \%$, ao passo que para as sementes de cebola houve decréscimo linear na sincronia do processo de germinação de 0,01241 para cada $0,01 \mathrm{mg} \mathrm{mL}^{-1}$ de extrato adicionado (Figura 1). As demais variáveis não apresentaram diferenças significativas entre as concentrações (Figura 1 e Tabela 1). 

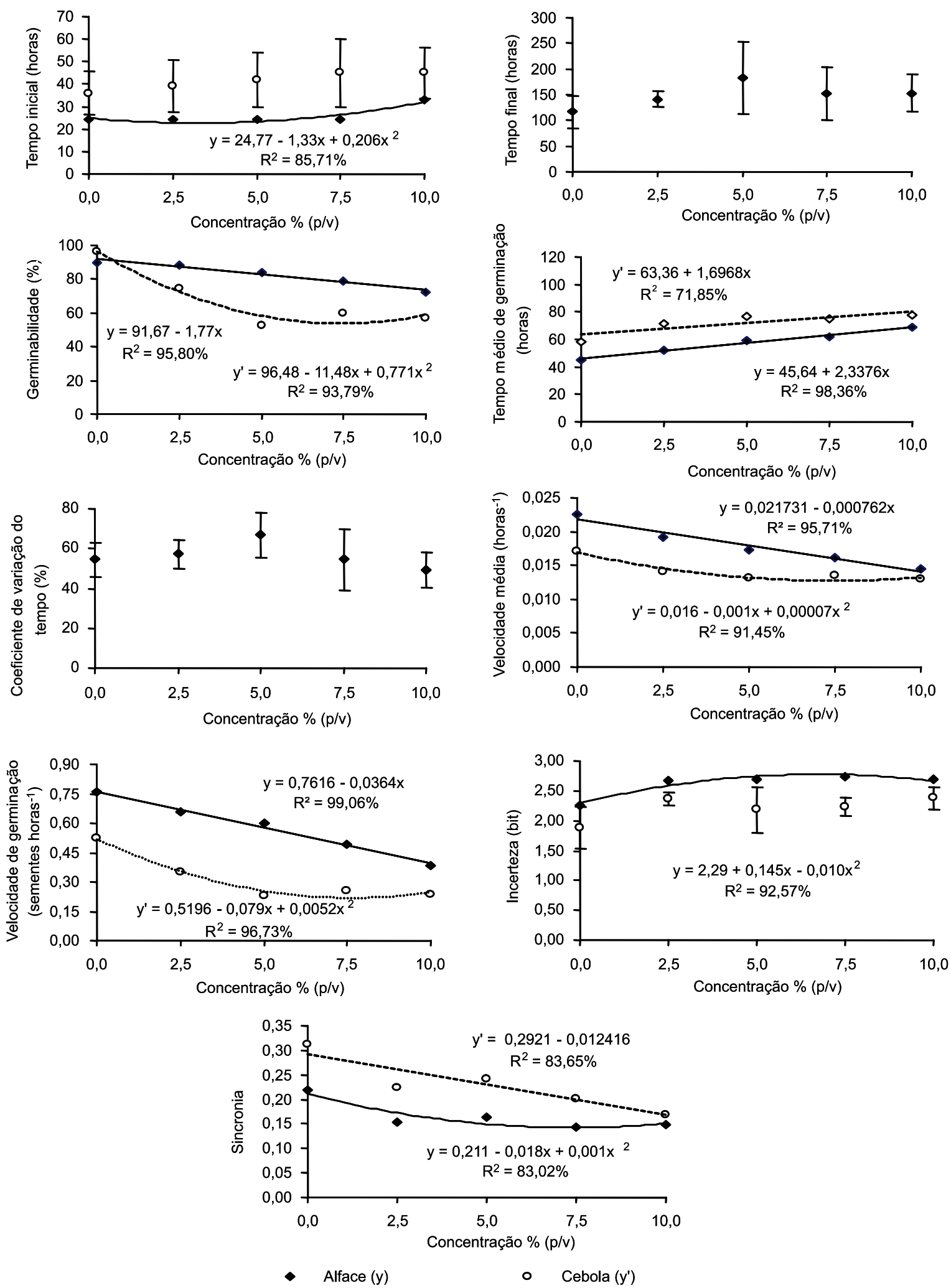

Figura 1 - Tempo inicial e final, germinabilidade, tempo médio de germinação, coeficiente de variação do tempo, velocidade média de germinação, velocidade de germinação, incerteza e sincronia do processo de germinação de diásporos de Lactuca sativa (alface) e Allium cepa (cebola) submetidos à ação do extrato de fruto de Sapindus saponaria em diferentes concentrações. 
Tabela 1 - Germinação de diásporos de Lactuca sativa (alface), Allium cepa (cebola), Echinochloa crus-galli (capim-arroz) e Ipomoea grandifolia (corda-de-viola) submetidos à ação do extrato de frutos de Sapindus saponaria em diferentes concentrações

\begin{tabular}{|c|c|c|c|c|c|c|c|c|c|}
\hline \multirow{2}{*}{$\begin{array}{l}\text { Variáveis } \\
\text { (unidades) }\end{array}$} & \multirow{2}{*}{ Controle } & \multirow{2}{*}{$2,5 \%$} & \multirow{2}{*}{$5,0 \%$} & \multirow{2}{*}{$7,5 \%$} & \multirow{2}{*}{$10,0 \%$} & \multicolumn{4}{|c|}{ Estatística } \\
\hline & & & & & & $\mathrm{W}(\mathrm{P})$ & ${ }^{1 /} F(P)$ & $\stackrel{2}{2}^{F}(P)$ & $H(P)$ \\
\hline \multicolumn{10}{|c|}{ Lactuca sativa } \\
\hline${ }^{3 /} T_{f}(\mathrm{~h})$ & $117,00 \pm 31,56 \mathrm{a}$ & $141,00 \pm 15,10 \mathrm{a}$ & $183,00 \pm 70,23 \mathrm{a}$ & $153,00 \pm 51,26 \mathrm{a}$ & $153,00 \pm 35,83 \mathrm{a}$ & $\begin{array}{c}\mathbf{0 , 8 7 1 8} \\
(0,0119) \\
\end{array}$ & $\begin{array}{l}\mathbf{1 , 9 1 6} \\
(0,16) \\
\end{array}$ & $\begin{array}{c}1,253 \\
(0,3312)\end{array}$ & \\
\hline $\mathrm{CV}_{t}(\%)$ & $54,49 \pm 8,50 \mathrm{a}$ & $57,11 \pm 7,30 \mathrm{a}$ & $66,74 \pm 11,43$ a & $54,48 \pm 15,55 \mathrm{a}$ & $49,32 \pm 9,10 \mathrm{a}$ & $\begin{array}{c}\mathbf{0 , 9 3 3 5} \\
(0,1899)\end{array}$ & $\begin{array}{c}\mathbf{0 , 7 2 7} \\
(0,5869)\end{array}$ & $\begin{array}{c}1,419 \\
(0,2754)\end{array}$ & \\
\hline \multicolumn{10}{|c|}{ Allium cepa } \\
\hline$T_{i}(\mathrm{~h})$ & $36,00 \pm 9,80 \mathrm{a}$ & $39,00 \pm 11,49 \mathrm{a}$ & $42,00 \pm 12,00 \mathrm{a}$ & $45,00 \pm 15,10 \mathrm{a}$ & $45,00 \pm 11,49 \mathrm{a}$ & $\begin{array}{c}\mathbf{0 , 9 4 0 4} \\
(0,2556) \\
\end{array}$ & $\begin{array}{c}\mathbf{0 , 2 5 4} \\
(0,903) \\
\end{array}$ & $\begin{array}{c}0,418 \\
(0,7931) \\
\end{array}$ & \\
\hline$T_{f}(\mathrm{~h})$ & $102,00 \pm 31,75 \mathrm{a}$ & $159,00 \pm 15,10 \mathrm{ab}$ & $150,00 \pm 39,80 \mathrm{ab}$ & $114,00 \pm 15,49 \mathrm{a}$ & $132,00 \pm 21,91 \mathrm{a}$ & $\begin{array}{c}\mathbf{0 , 9 7 0 6} \\
(0,7572) \\
\end{array}$ & $\begin{array}{c}\mathbf{1 , 0 1 5} \\
(0,4311) \\
\end{array}$ & $\begin{array}{c}\mathbf{3 , 2 1 4} \\
(0,043) \\
\end{array}$ & \\
\hline $\mathrm{CV}_{t}(\%)$ & $25,05 \pm 7,76 \mathrm{a}$ & $39,29 \pm 3,66 \mathrm{ab}$ & $36,13 \pm 14,67 a b$ & $23,35 \pm 2,49 \mathrm{a}$ & $27,15 \pm 5,33 \mathrm{a}$ & $\begin{array}{c}\mathbf{0 , 9 2 9 5} \\
(0,1599) \\
\end{array}$ & $\begin{array}{c}\mathbf{2 , 2 5 1} \\
(0,1122) \\
\end{array}$ & $\begin{array}{c}\mathbf{3 , 1 0 1} \\
(0,0479) \\
\end{array}$ & \\
\hline$I$ (bit) & $1,8808 \pm 0,3462 \mathrm{a}$ & $2,3567 \pm 0,1105 \mathrm{a}$ & $2,1847 \pm 0,3814 \mathrm{a}$ & $2,2318 \pm 0,1558 \mathrm{a}$ & $2,3766 \pm 0,1874 \mathrm{a}$ & $\begin{array}{c}\mathbf{0 , 9 6 3 2} \\
(0,6096)\end{array}$ & $\begin{array}{c}\mathbf{1 , 9 3 5} \\
(0,1568)\end{array}$ & $\begin{array}{c}2,355 \\
(0,1007)\end{array}$ & \\
\hline \multicolumn{10}{|c|}{ Echinochloa crus-galli } \\
\hline$T_{f}(\mathrm{~h})$ & $144,00 \pm 60,40 \mathrm{a}$ & $108,00 \pm 9,80 \mathrm{a}$ & $117,00 \pm 18,00 \mathrm{a}$ & $168,00 \pm 45,96 \mathrm{a}$ & $132,00 \pm 48,99 \mathrm{a}$ & $\begin{array}{c}\mathbf{0 , 9 3 3 8} \\
(0,1929) \\
\end{array}$ & $\begin{array}{c}\mathbf{2 , 0 0 5} \\
(0,1455) \\
\end{array}$ & $\begin{array}{c}1,297 \\
(0,3156) \\
\end{array}$ & \\
\hline $\mathrm{CV}_{t}(\%)$ & $34,03 \pm 13,16 \mathrm{a}$ & $26,55 \pm 6,04 \mathrm{a}$ & $25,14 \pm 5,67 \mathrm{a}$ & $34,46 \pm 12,89 a$ & $23,82 \pm 11,27 \mathrm{a}$ & $\begin{array}{c}\mathbf{0 , 9 4 6 8} \\
(0,3336) \\
\end{array}$ & $\begin{array}{c}\mathbf{0 , 9 7 6} \\
(0,4495) \\
\end{array}$ & $\begin{array}{c}0,959 \\
(0,4581) \\
\end{array}$ & \\
\hline$I$ (bit) & $2,3044 \pm 0,3206 \mathrm{a}$ & $2,2275 \pm 0,1778 \mathrm{a}$ & $2,1633 \pm 0,1892 \mathrm{a}$ & $2,3529 \pm 0,2589 \mathrm{a}$ & $2,1408 \pm 0,2690 \mathrm{a}$ & $\begin{array}{c}\mathbf{0 , 9 6 4 4} \\
(0,6336)\end{array}$ & $\begin{array}{c}\mathbf{0 , 4 4 2} \\
(0,7761)\end{array}$ & $\begin{array}{c}0,529 \\
(0,7165)\end{array}$ & \\
\hline$Z$ & $0,1989 \pm 0,0427 \mathrm{a}$ & $0,2277 \pm 0,0359 \mathrm{a}$ & $0,2321 \pm 0,0536 \mathrm{a}$ & $0,1928 \pm 0,0377 \mathrm{a}$ & $0,2060 \pm 0,0480 \mathrm{a}$ & $\begin{array}{c}\mathbf{0 , 9 5 0 4} \\
(0,3845) \\
\end{array}$ & $\begin{array}{c}\mathbf{0 , 3 5 4} \\
(0,8372) \\
\end{array}$ & $\begin{array}{c}0,632 \\
(0,6472) \\
\end{array}$ & \\
\hline \multicolumn{10}{|c|}{ Ipomoea grandifolia } \\
\hline$T_{f}(\mathrm{~h})$ & $63,00 \pm 24,74 \mathrm{a}$ & $45,00 \pm 28,35 \mathrm{a}$ & $69,00 \pm 18,00 \mathrm{a}$ & $78,00 \pm 12,00 \mathrm{a}$ & $63,00 \pm 11,49 \mathrm{a}$ & $\begin{array}{c}\mathbf{0 , 9 4 7 4} \\
(0,3409) \\
\end{array}$ & $\begin{array}{c}\mathbf{2 , 2 2 2} \\
(0,1156) \\
\end{array}$ & $\begin{array}{c}1,446 \\
(0,2673)\end{array}$ & \\
\hline $\mathrm{G}(\%)$ & $79,17 \pm 3,19 \mathrm{a}$ & $63,33 \pm 2,72 b$ & $74,17 \pm 3,19 \mathrm{ab}$ & $74,17 \pm 1,67 \mathrm{ab}$ & $47,5 \pm 12,87 \mathrm{c}$ & $\begin{array}{c}0,8045 \\
(0,0007)\end{array}$ & $\begin{array}{c}\mathbf{4 , 6 1 5} \\
(0,0125) \\
\end{array}$ & & $\begin{array}{r}\mathbf{1 6 , 2 3 1} \\
(0,002)\end{array}$ \\
\hline $\mathrm{CV}_{t}(\%)$ & $63,61 \pm 17,19 \mathrm{a}$ & $48,49 \pm 15,82 \mathrm{a}$ & $52,11 \pm 11,02 \mathrm{a}$ & $50,53 \pm 11,73 a$ & $35,48 \pm 5,74 \mathrm{a}$ & $\begin{array}{c}\mathbf{0 , 9 4 7 8} \\
(0,3463) \\
\end{array}$ & $\begin{array}{c}\mathbf{3 , 0 1 6} \\
(0,052) \\
\end{array}$ & $\begin{array}{c}2,406 \\
(0,0955) \\
\end{array}$ & \\
\hline$I$ (bit) & $1,3902 \pm 0,0761 \mathrm{a}$ & $1,2472 \pm 0,5007 \mathrm{a}$ & $1,6600 \pm 0,2031 \mathrm{a}$ & $1,3992 \pm 0,2549 \mathrm{a}$ & $1,7217 \pm 0,1816 \mathrm{a}$ & $\begin{array}{c}\mathbf{0 , 9 1 6 1} \\
(0,0879) \\
\end{array}$ & $\begin{array}{c}\mathbf{2 , 8 0 9} \\
(0,0636)\end{array}$ & $\begin{array}{c}2,015 \\
(0,1439)\end{array}$ & \\
\hline$Z$ & $0,4198 \pm 0,0235 \mathrm{a}$ & $0,4435 \pm 0,1366 \mathrm{a}$ & $0,3758 \pm 0,0912 \mathrm{a}$ & $0,4758 \pm 0,1201 \mathrm{a}$ & $0,2997 \pm 0,0578 \mathrm{a}$ & $\begin{array}{c}\mathbf{0 , 9 6 9 8} \\
(0,7413) \\
\end{array}$ & $\begin{array}{c}\mathbf{3 , 0 7 1} \\
(0,0493) \\
\end{array}$ & $\begin{array}{c}2,055 \\
(0,1379) \\
\end{array}$ & \\
\hline
\end{tabular}

Médias seguidas por letras iguais na linha não diferem entre si pelo teste de Tukey a 0,05 de probabilidade; $t_{i}$ : tempo inicial; $t_{f}$ tempo final; $G$ : germinabilidade; $C V$ : coeficiente de variação do tempo de germinação; $I$ : incerteza; $Z$ : sincronia; $W$ : estatística do teste de Shapiro-Wilk - valores em negrito indicam que os resíduos seguem distribuição normal $(P>0,01) ;{ }^{1 /} F$ : estatística do teste de Levene - valores em negrito indicam homogeneidade entre as variâncias $(P>0,01)$; ㄹ $F$ : estatística do teste de Snedecor - valores em negrito indicam diferença significativa entre as concentrações (ANOVA; $P<0,05$ ); $H$ : estatística do teste de Kruskal-Wallis - valores em negrito indicam diferença significativa entre as concentrações $(P<0,05)$; $P$ : probabilidade. ${ }^{3 /}$ Dados transformados em raiz $(\mathrm{x})$ para realização das análises estatísticas; dados apresentados representam valores originais.

Os resultados mostram que diversas variáveis do processo de germinação foram afetadas pelos compostos do extrato de frutos de Sapindus saponaria. Como citado por Ferreira \& Áquila (2000), muitas vezes o efeito alelopático não é apenas sobre a germinabilidade, mas também sobre a velocidade de germinação ou outras características do processo, o que evidencia a influência do aleloquímico no metabolismo das sementes.

Verificou-se, em outros trabalhos, que o efeito dos extratos de frutos de juazeiro (Ziziphus joazeiro) sobre a germinação das cipselas de alface também foi dependente da concentração (Oliveira et al., 2009).
Entretanto, extratos de frutos verdes e maduros de Mimosa bimucronata (Jacobi \& Ferreira, 1991) e de Aristolochia esperanzae (Gatti et al., 2004) não inibiram o processo germinativo das cipselas de alface.

$\mathrm{Na}$ análise morfológica das plântulas de hortaliças, a porcentagem de plântulas normais de alface e cebola foi nula a partir da concentração de 2,5 e $5 \%$, respectivamente. No entanto, para ambas as espécies, na concentração de $10 \%$, nenhuma plântula sobreviveu, o que mostra a eficiência do efeito desse extrato em alterar a morfologia e inibir o desenvolvimento dessas plântulas (Figuras 2 e 3). Com isso, o comprimento da parte aérea 
e da raiz primária das plântulas de alface foi nulo a partir das concentrações de 7,79 e $7,58 \%$, respectivamente. Quanto às plântulas de cebola, verificou-se decréscimo linear no comprimento da parte aérea de $3,839 \mathrm{~mm}$ para cada $0,01 \mathrm{mg} \mathrm{mL}^{-1}$ de extrato adicionado, e no comprimento radicular, valores nulos a partir da concentração de 7,09\% (Figuras 2 e 3).

Tabela 2 - Teste F para comparar os coeficientes angulares das regressões lineares oriundas do teste de germinação de diásporos de Lactuca sativa (alface), Allium cepa (cebola), Echinochloa crus-galli (capim-arroz) e Ipomoea grandifolia (corda-de-viola) submetidos à ação do extrato de frutos de Sapindus saponaria

\begin{tabular}{|c|c|c|}
\hline Variáveis (unidades) & 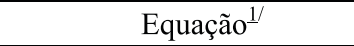 & $\mathrm{F}_{\text {calculado }}$ \\
\hline \multicolumn{3}{|c|}{ Lactuca sativa $\mathrm{x}$ Allium cepa } \\
\hline Tempo médio de germinação (h) & $\begin{array}{l}y=45,54+2,3376 x \\
y^{\prime}=63,36+1,6968 x\end{array}$ & $3,03^{\mathrm{ns}}$ \\
\hline \multicolumn{3}{|c|}{ Echinochloa crus-galli x Ipomoea grandifolia } \\
\hline Tempo médio de germinação (h) & $\begin{array}{l}y=64,93+1,7546 x \\
y^{\prime}=17,897+1,5339 x\end{array}$ & $0,5727^{\mathrm{ns}}$ \\
\hline Velocidade média de germinação $\left(\mathrm{h}^{-1}\right)$ & $\begin{array}{l}y=0,015319-0,00032 x \\
y^{\prime}=0,054175-0,002481 x\end{array}$ & $46,96^{*}$ \\
\hline Velocidade de germinação (semente $\mathrm{h}^{-1}$ ) & $\begin{array}{l}y=0,403517-0,015185 x \\
y^{\prime}=1,5323-0,095189 x\end{array}$ & $93,04^{*}$ \\
\hline
\end{tabular}

${ }^{1 /} \mathrm{H}_{0}: \beta_{1}-\beta_{2}=0$, em que $\beta_{1}$ e $\beta_{2}$ são os parâmetros dos coeficientes angulares das equações. y: capim-arroz; y': corda-de-viola. ${ }^{\text {ns: coeficientes }}$ angulares para as duas espécies não diferem entre si significativamente. *: coeficientes angulares para as duas espécies diferem significativamente entre si $\left(\mathrm{F}_{\text {calculado }}>\mathrm{F}_{\text {tabelado }}\right)$.
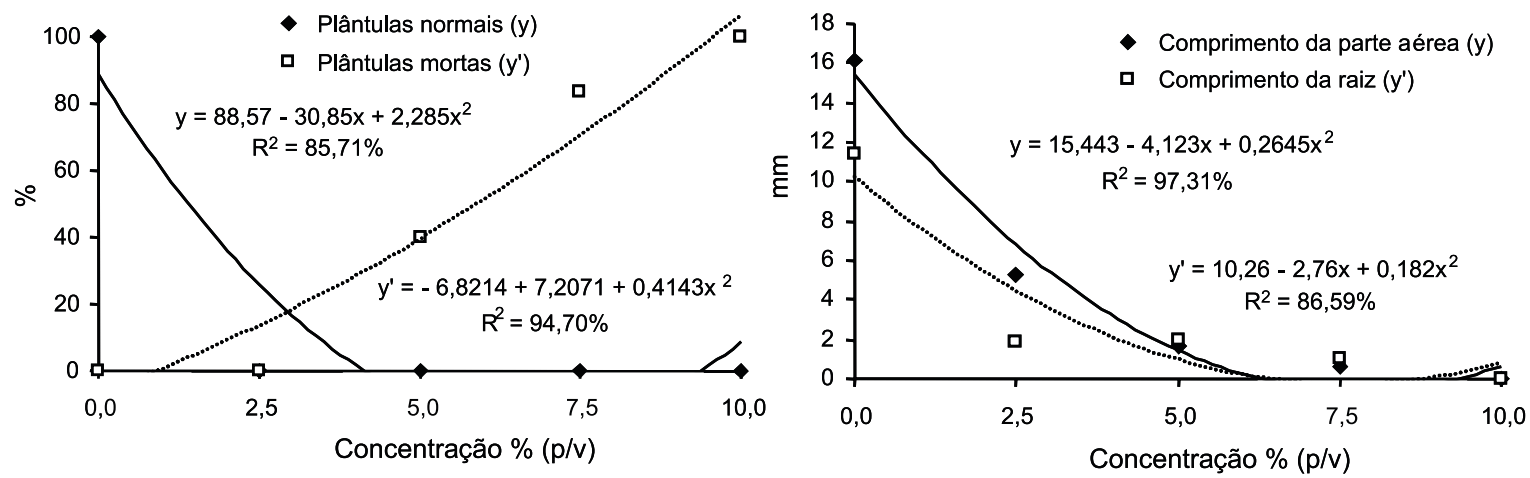

Figura 2 - Porcentagem de plântulas normais, plântulas mortas, comprimento da parte aérea e da raiz de plântulas de Lactuca sativa (alface) submetidas à ação do extrato de frutos de Sapindus saponaria em diferentes concentrações.
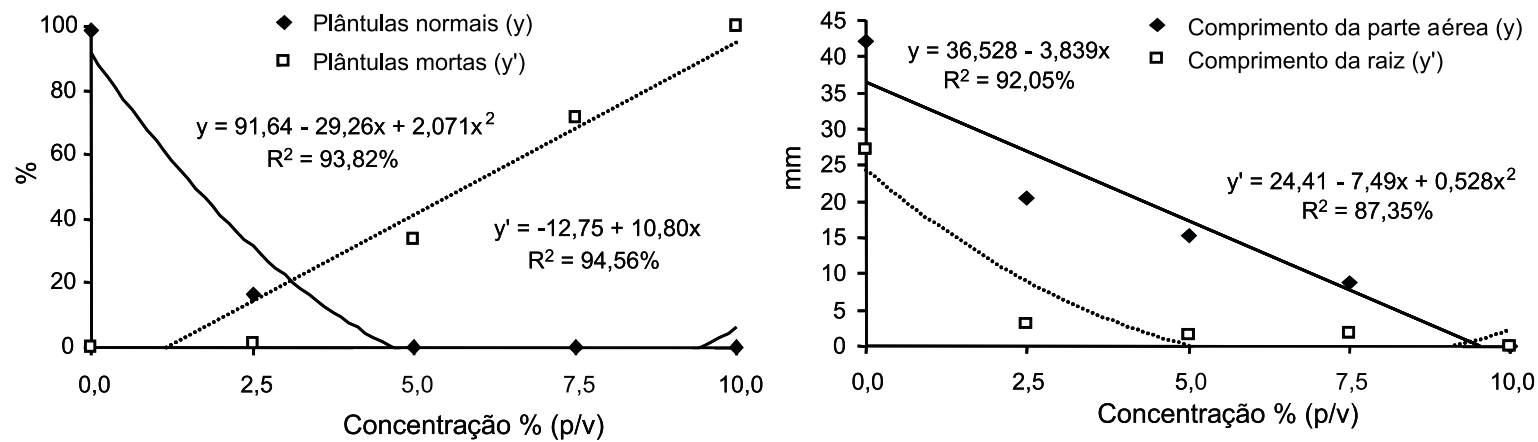

Figura 3 - Porcentagem de plântulas normais, plântulas mortas, comprimento da parte aérea e da raiz de plântulas de Allium cepa (cebola) submetidas à ação do extrato de frutos de Sapindus saponaria em diferentes concentrações. 
Anomalias morfológicas e perda de vigor das plântulas de alface já foram demonstradas numa investigação com extratos de Ilex paraguariensis (Áquila, 2000). Segundo Maraschin-Silva \& Aqüila (2006), muitas fitotoxinas são capazes de afetar a morfologia e a anatomia de plântulas, o que pode ser evidenciado por endurecimento e escurecimento dos ápices radiculares, fragilidade e aumento de ramificações.

O extrato do fruto de Sapindus saponaria também exerceu efeito alelopático sobre os diásporos das plantas daninhas. Verificou-se acréscimo linear no tempo inicial (1,92 hora para cada $0,01 \mathrm{mg} \mathrm{mL}^{-1}$ de extrato, para o capim-arroz) e no tempo médio de germinação (1,75 hora para o capim-arroz e 1,53 hora para a corda-de-viola, para cada $0,01 \mathrm{mg} \mathrm{mL}^{-1} \mathrm{de}$ extrato) (Figura 4). Para as sementes de cordade-viola, o tempo inicial de germinação foi de 12 horas até a concentração de $7,5 \%$, chegando a 21 horas na concentração de 10\%. Observou-se redução linear na germinabilidade $\left(1,53\right.$ hora para cada $0,01 \mathrm{mg} \mathrm{mL}^{-1} \mathrm{de}$ extrato, para o capim-arroz), na velocidade média $\left(0,0003\right.$ hora $^{-1}$ para o capim-arroz e 0,0024 hora $^{-1}$ para a corda-de-viola, para cada $0,01 \mathrm{mg} \mathrm{mL}^{-1}$ de extrato) e na velocidade de germinação $\left(0,0151\right.$ e 0,0951 semente hora ${ }^{-1}$ para cada $0,01 \mathrm{mg} \mathrm{mL}^{-1}$ de extrato, para o capim-arroz e corda-de-viola, respectivamente), indicando redução e atraso na germinação das sementes na concentração de $10 \%$ (Figura 4).

Os valores de germinabilidade das sementes de corda-de-viola não apresentaram ajustes aos modelos de regressão, porém na concentração de $10 \%$ foi registrada a menor porcentagem de germinação dessas sementes $(47,5 \%)$ (Tabela 1). As demais variáveis não mostraram diferenças significativas entre os tratamentos (Figura 4 e Tabela 1).

Comparando as linhas de tendência das regressões lineares, observou-se que para o tempo médio de germinação os diásporos das duas espécies daninhas apresentaram as mesmas taxas de incremento, enquanto para a velocidade média e velocidade de germinação os decrementos foram maiores para as cariopses de capim-arroz (Tabela 2). Comparando as duas espécies daninhas, notou-se que as sementes de corda-de-viola apresentaram maior velocidade média de germinação do que as cariopses de capim-arroz, e isso pode estar relacionado com a escarificação a que essas sementes foram submetidas (Figura 4).

O efeito do extrato dos frutos de Sapindus saponaria foi expressivo sobre a morfologia das plântulas das espécies daninhas. As plântulas normais de capim-arroz variaram de 98,75\% (controle) a 6,25\% (concentração de 10\%), enquanto para a corda-de-viola essa variação foi de $90 \%$ (controle) a $0 \%$ (a partir da concentração de 5\%) (Figuras 5 e 6). Constatou-se aumento, em relação ao controle, de 6,25 e $8,75 \%$ de plântulas mortas de capim-arroz e corda-de-viola, respectivamente, na concentração de $10 \%$. O comprimento da parte aérea das plântulas de capim-arroz sofreu decréscimo linear de 2,248 $\mathrm{mm}$, para cada $0,01 \mathrm{mg} \mathrm{mL}^{-1}$ de extrato; para a corda-de-viola, o menor comprimento $(14,77 \mathrm{~mm})$ ocorreu na concentração de $8,40 \%$. As plântulas de capim-arroz e corda-de-viola apresentaram valores mínimos $(0 \mathrm{~mm})$ para o comprimento da raiz nas concentrações de 7,12 e $7,19 \%$, respectivamente (Figuras 5 e 6).

A raiz das plântulas das espécies daninhas estudadas foi o órgão mais afetado pelo extrato aplicado, sendo a redução de tamanho e a necrose os sintomas mais comuns. Esses efeitos são semelhantes aos danos provocados por detergentes naturais, como as saponinas (Soares \& Vieira, 2000). Alguns autores sugerem que o efeito mais acentuado sobre as raizes deve-se ao contato mais intimo destas com a solução de aleloquímicos (MaraschinSilva \& Aqüila, 2006).

O extrato do fruto de Sapindus saponaria foi tóxico tanto para as hortaliças quanto para as plantas daninhas, uma vez que inibiu a germinação dos diásporos, induziu a presença de anomalias nas estruturas das plântulas e reduziu o crescimento das plântulas normais. O efeito do extrato foi mais intenso sobre a morfologia das plântulas do que sobre o processo de germinação dos diásporos, conforme já registrado por outros autores (Maraschin-Silva \& Aqüila, 2006; Souza et al., 2010).

Quanto ao indice de resposta ao efeito alelopático (RI), observou-se que os diásporos 

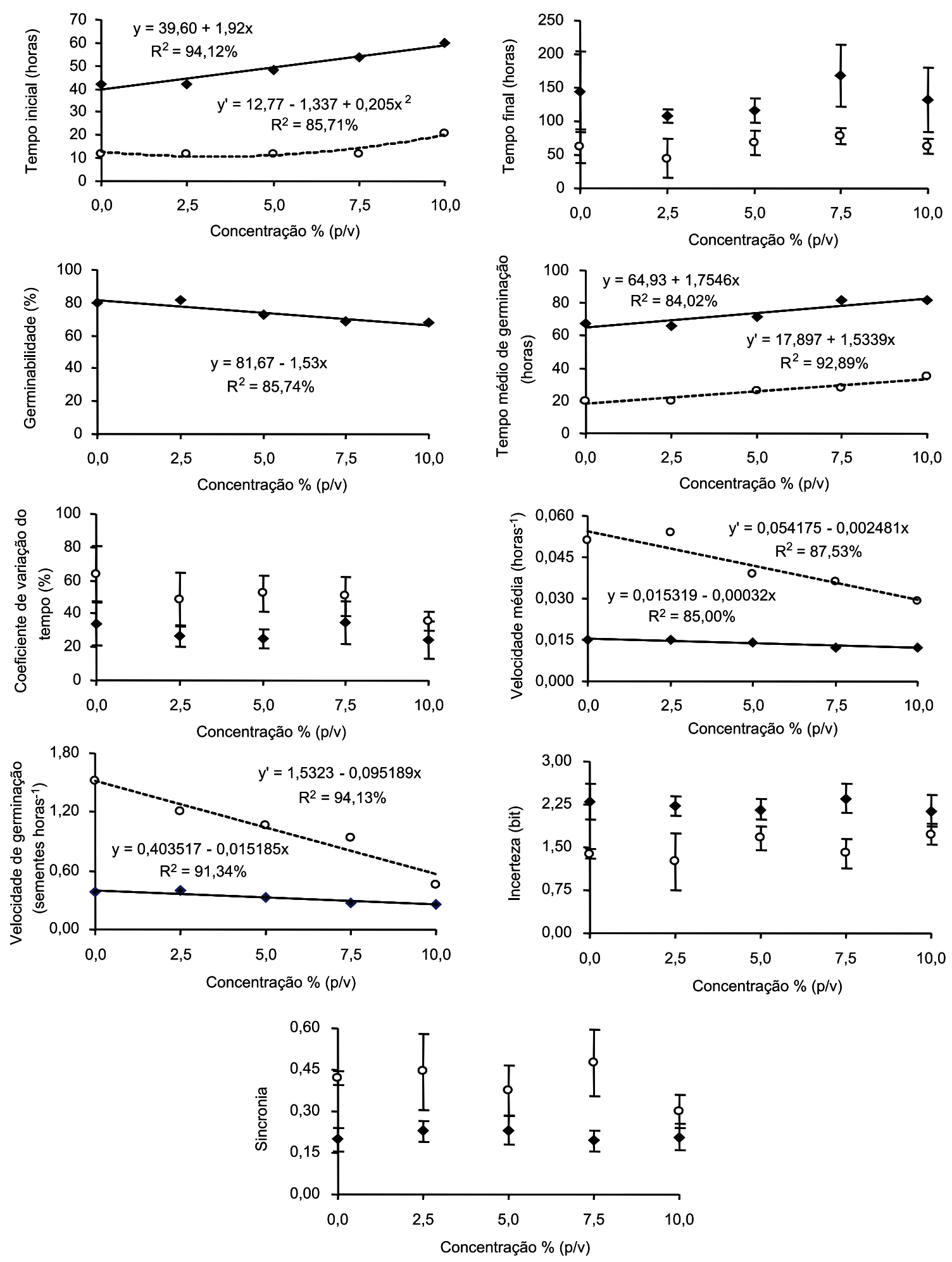

- Capim-arroz (y) o Corda-de-viola (y')

Figura 4 - Tempo inicial e final, germinabilidade, tempo médio de germinação, coeficiente de variação do tempo, velocidade média de germinação, velocidade de germinação, incerteza e sincronia do processo de germinação de diásporos de Echinochloa crus-galli (capim-arroz) e Ipomoea grandifolia (corda-de-viola) submetidos à ação do extrato de frutos de Sapindus saponaria em diferentes concentrações. 

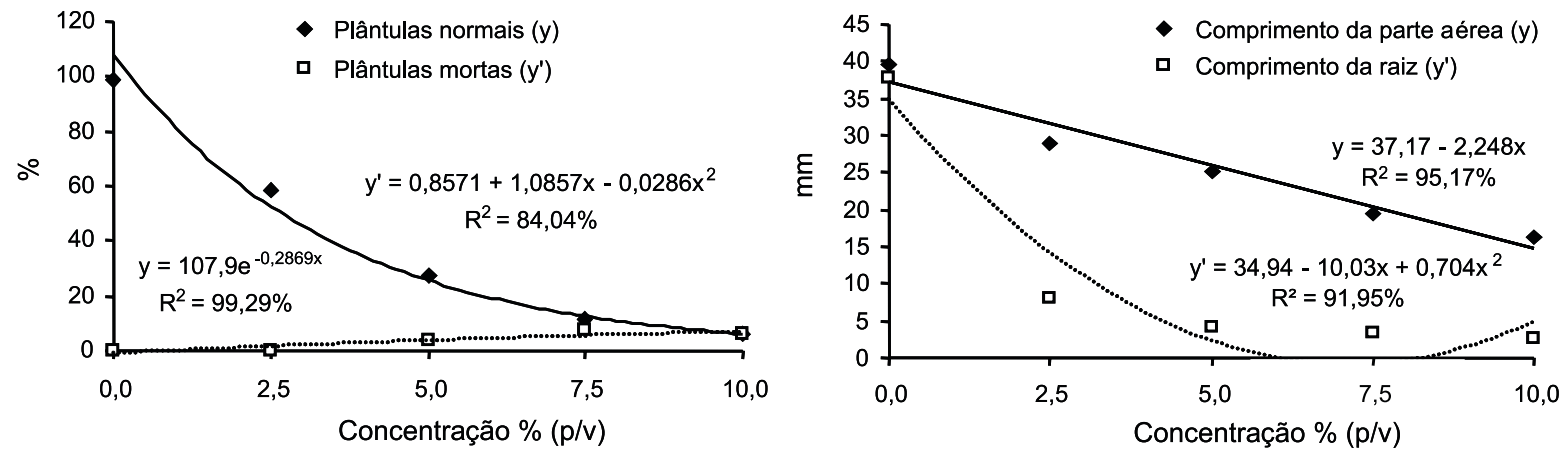

Figura 5 - Porcentagem de plântulas normais, plântulas mortas, comprimento da parte aérea e da raiz de plântulas de Echinochloa crus-galli (capim-arroz) submetidas à ação do extrato de frutos de Sapindus saponaria em diferentes concentrações.
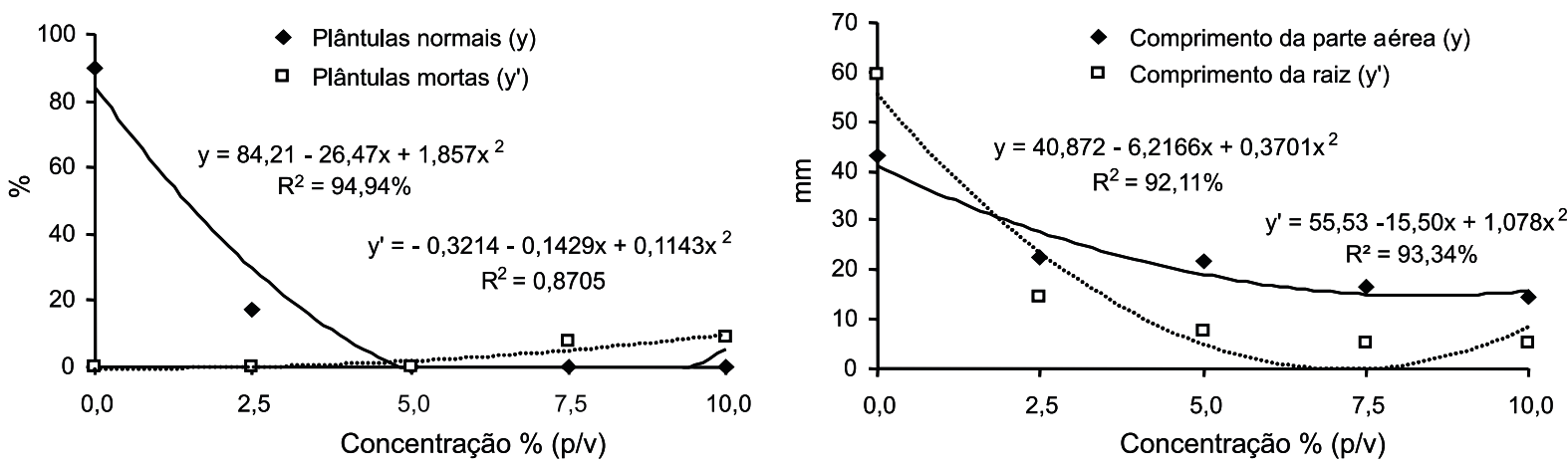

Figura 6 - Porcentagem de plântulas normais, plântulas mortas, comprimento da parte aérea e da raiz de plântulas de Ipomoea grandifolia (corda-de-viola) submetidas à ação do extrato de frutos de Sapindus saponaria em diferentes concentrações.

de alface, cebola e corda-de-viola mostraram valores negativos para todas as concentrações, indicando que o extrato de frutos de Sapindus saponaria exerceu forte efeito inibitório sobre o processo de germinação desses diásporos (Figura 7). No entanto, o efeito alelopático sobre as cariopses de capim-arroz foi menor, apresentando RI positivo na concentração de 2,5\% (Figura 7).

Com relação às características físico-químicas, o $\mathrm{pH}$ do extrato de frutos de Sapindus saponaria foi de 6,61, e o potencial osmótico, de -0,18 MPa. Considerando-se que a germinação e o desenvolvimento de plântulas são afetados negativamente em condições de extrema acidez ou extrema alcalinidade (Souza Filho et al., 1996), verificou-se que o $\mathrm{pH}$ desse extrato não interferiu nesses processos.

Quando colocadas para germinar em soluções de PEG-6000, as cipselas de alface germinaram, em média, 89 e $86 \%$ nos potenciais de 0 e $-0,2 \mathrm{MPa}$, respectivamente, enquanto para a cebola 90 e $89 \%$ das sementes germinaram nesses potenciais,

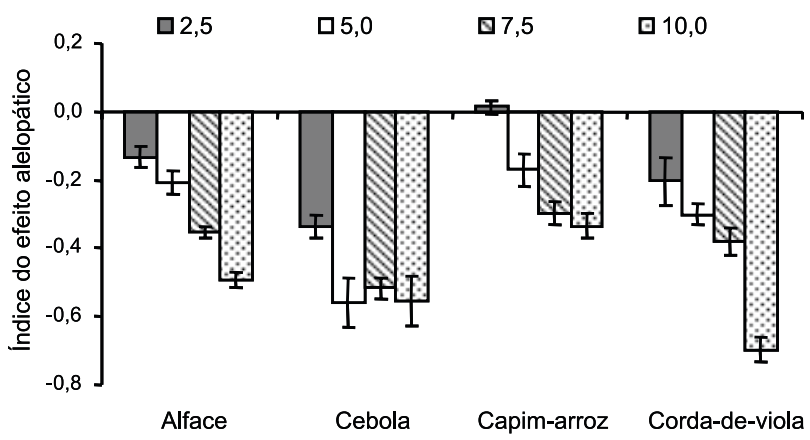

Figura 7 - Índice de resposta ao efeito alelopático dos diásporos de alface (Lactuca sativa), cebola (Allium cepa), capim-arroz (Echinochloa crus-galli) e corda-de-viola (Ipomoea grandifolia) submetidos à ação do extrato de frutos de Sapindus saponaria em diferentes concentrações. As barras verticais representam o erro-padrão da média. 
respectivamente. Os diásporos de capim-arroz e corda-de-viola germinaram, em média, $80 \%$ nos potenciais de 0 e -0,2 MPa. Considerando que soluções com potencial osmótico de -0,2 MPa não interferiram significativamente na germinabilidade desses diásporos, pode-se inferir que a redução na porcentagem de germinação tenha acontecido, principalmente, pela presença de substâncias com atividade alelopática nesses extratos.

Estudos revelaram a presença de vários metabólitos secundários, entre eles as saponinas, nos frutos de Sapindus saponaria (Pelegrini et al., 2008), e essas substâncias podem estar associadas aos efeitos alelopáticos da espécie. Uma das teorias mais aceitas para explicar a alta concentração de saponinas em muitas espécies de plantas é que estas funcionariam como proteção ao ataque de patógenos, sejam estes fungos, bactérias ou virus (Sparg et al., 2004).

As saponinas podem ter ação indireta ou direta. Os efeitos indiretos incluem alterações nas propriedades e fertilidade do solo, bem como nas populações e atividades de microrganismos. Quanto aos efeitos diretos, que são os mais estudados, estes incluem alterações no metabolismo vegetal, podendo alterar as características citológicas, as propriedades das membranas, a divisão celular, os fitormônios, a germinação, a absorção mineral, a respiração e a atividade enzimática (Rizvi et al.,1992).

Dessa forma, pode-se afirmar que os extratos de frutos de Sapindus saponaria possuem potencialidades alelopáticas, atuando tanto sobre hortaliças quanto sobre as espécies daninhas. Além disso, o efeito inibitório sobre o processo de germinação dos diásporos e morfologia das plântulas de alface, cebola, capim-arroz e corda-de-viola foi dependente da concentração. Com isso, deduz-se que o potencial do extrato proveniente dos frutos de Sapindus saponaria pode atuar como um herbicida a ser utilizado em práticas de agricultura sustentável.

\section{AGRADECIMENTOS}

Ao Sr. José Roberto Sanches, pela determinação do potencial osmótico; à CAPES e ao CNPq, pelo apoio financeiro.

\section{LITERATURA CITADA}

ALBIERO, A. L. M.; BACCHI, E. M.; MOURÃO, K. S. M. Caracterização anatômica das folhas, frutos e sementes de Sapindus saponaria L. (Sapindaceae). Acta Sci., v. 23, n. 2, p. 49-560, 2001.

AQÜILA, M. E. A. Efeito alelopático de Ilex paraguariensis A. St.-Hil. na germinação e crescimento inicial de Lactuca sativa L. Iheringia, v. 53, p. 51-66, 2000.

AZANIA, A. A. P. M. et al. Métodos de superação de dormência em sementes de Ipomoea e Merremia.

Planta Daninha, v. 21, n. 2, p. 203-209, 2003.

BRASIL. Ministério da Agricultura, Pecuária e Abastecimento. Regras para análise de sementes. Secretaria de Defesa Agropecuária. Brasília: Mapa/ACS, 2009. 399 p.

CONCENÇO, G. et al. Método rápido para detecção de resistência de capim-arroz (Echinochloa spp.) ao quinclorac. Planta Daninha, v. 26, n. 2, p. 429-437, 2008.

FERREIRA, A. G.; ÁQUILA, M. E. A. Alelopatia: uma área emergente da ecofisiologia. R. Bras. Fisiol. Veg., v. 12, p. 175-204, 2000.

$\mathrm{GAO}, \mathrm{X}$. et al. Allelopathic effect of Hemistepta lyrata on the germination and growth of wheat, sorghum, cucumber, rape and radish seeds. Weed Biol. Manag., v. 9, p. 243-249, 2009.

GATTI, A. B.; PEREZ, S. C. J. G. A.; LIMA, M. I. S. Atividade alelopática de extratos aquosos de Aristolochia esperanzae $\mathrm{O}$. Kuntze na germinação e no crescimento de Lactuca sativa L. e Raphanus sativus L. Acta Bot. Bras., v. 18 , n. 3, p. 459-472, 2004

JACOBI, U. S.; FERREIRA, A. G. Efeitos alelopáticos de Mimosa bimucronata (DC). sobre espécies cultivadas. Pesq. Agropec. Bras., v. 6, p. 935-943, 1991.

KOHLI, R. K.; BATISH, D.; SINGH, H. P. Allelopathic interactions in agroecosystems. In: REIGOSA M.J.; PEDROL, N.; GONZÁLEZ L. (Eds.), Allelopathy: a physiological process with ecological implications. Dordrecht: Springer, 2006. p. 465-493

KÖPPEN, W. Climatologia: com um estúdio de los climas de la tierra. México: Fondo de Cultura Econômica, 1948. $478 \mathrm{p}$.

MARASCHIN-SILVA, F.; AQÜILA, M. E. A. Potencial alelopático de espécies nativas na germinação e crescimento inicial de Lactuca sativa L. (Asteraceae). Acta Bot. Bras., v. 20, n. 1, p. 61-69, 2006.

Planta Daninha, Viçosa-MG, v. 29, n. 2, p. 311-322, 2011 
MAULI, M. M. et al. Leucaena allelopathy on weeds and soybean seed germination. Semina-Ciências Agrárias, v. 30, n. 1, p. 55-62, 2009.

OLIVEIRA, A. K. et al. Alelopatia em extratos de frutos de juazeiro (Ziziphus joazeiro Mart. - Rhamnaceae). Acta Bot. Bras., v. 23, n. 4, p. 1186-1189, 2009.

PELEGRINI, D. D. et al. Biological activity and isolated compounds in Sapindus saponaria L. and other plants of the genus Sapindus. Latin Am. J. Pharmacy, v. 27, n. 6, p. $922-927,2008$

RANAL, M. A.; SANTANA, D. G. How and why to measure the germination process? R. Bras. Bot., v. 29, p. 1-11, 2006.

RIZVI, S. J. H. et al. A discipline called allelopathy.. In: RIZVI, S. J. H.; RIZVI, V. (Eds.). Allelopathy: basic and applied aspects. London: Chapman \& Hall, 1992 . p. 1-10

SILVA, H. L. et al. Determinação de espécie indicadora e comparação de genótipos de girassol quanto ao potencial alelopático. Planta Daninha, v. 27, n. 4, p. 655-663, 2009.

SOARES, G. L. G.; VIEIRA, T. R. Inibição da germinação e do crescimento radicular de alface (cv. "Grand Rapids") por extratos aquosos de cinco espécies de Gleicheniaceae.

Flor. Amb., v. 7, n. 1, p. 180-197, 2000.
SOKAL, R. R.; ROHLF, F. J. Biometry: the principles and practice of statistics in biological research. New York: W. H. Freeman, 1997. 887 p

SOUZA FILHO, A. P. S.; RODRIGUES, L. R. A.; RODRIGUES, T. J. D. Efeitos de extratos aquosos de assapeixe sobre a germinação de três espécies de braquiária. Planta Daninha, v. 14, n. 2, p. 93-101, 1996

SOUZA, F. M. et al. Allelopathic potential of bark and leaves of Esenbeckia leiocarpa Engl. (Rutaceae). Acta Bot. Bras. v. 24, n. 1, p. $169-174,2010$

SPARG, S. G.; LIGHT, M. E.; van STADEN, J. Biological activities and distribution of plant saponins. J. Ethnopharm. v. 94, n. 1, p. 19-243, 2004.

VILLELA, F. A.; DONI FILHO, L.; SEQUEIRA, E. L. Tabela de potencial osmótico em função da concentração de polietileno glicol 6000 e da temperatura. Pesq. Agropec. Bras., v. 26, p. 1957-1968, 1991.

VYVYAN, J. R. Allelochemicals as leads for new herbicides and agrochemicals. Tetrahedron, v. 58, p. 1631-1646, 2002

YOUNG, G. P.; BUSH, J. K. Assessment of the allelopathic potential of Juniperus ashei on germination and growth of Bouteloua curtipendula. J. Chem. Ecol., v. 35, n. 1, p. 74-80, 2009. 